\title{
Caridade, meritocracia e redistribuição: a tríade histórica da política social e da extensão rural brasileira
}

\author{
Charity, meritocracy and redistribution: the historical triad of social policy and brazilian \\ rural extension
}

\author{
Márcio Maltarolli Quidá* \\ Adilson Vaz Cabral Filho**
}

\section{Resumo:}

Este artigo é um ensaio teórico que aborda a historiografia da institucionalidade política da extensão rural brasileira, destacando a similaridade com os eventos alusivos à evolução das políticas sociais desde seu nascedouro na Europa Ocidental. Apresenta a cronologia dos acontecimentos relacionados à extensão rural através de binômios propostos por Rodrigues (1997), a saber: humanismo-assistencialista, difusionismo-produtivista e humanismo-crítico; vis-àvis as fases residual-caritativa, meritocrático-particularista e institucional-redistributiva presentes na tipologia de Titmuss (1958), conhecida e usual, que leva em consideração a relação entre o público e o privado e o grau de redistribuição dos sistemas de proteção para explicar a evolução histórica das políticas sociais. Nas considerações finais apresenta um quadro comparativo da homogenia, evidenciando as características que aproximam a evolução das políticas sociais com as políticas de extensão rural.

Palavras-chave: Extensão rural. Política social. Caridade. Meritocracia. Redistribuição.

\begin{abstract}
:
This article is a theoretical essay that addresses the historiography of the political institutionality of the Brazilian rural extension, highlighting the similarity with the events alluding to the evolution of social policies since its birth in Western Europe. It presents the chronology of events related to rural extension through binomials proposed by Rodrigues (1997), namely: assistentialist-humanism, productivist-diffusionism and critical-humanism; vis-à-vis the residual-charitable, meritocraticparticularist and institutional-redistributive phases present in the typology of Titmuss (1958), known and usual, which takes into account the relationship between public and private and the degree of redistribution of protection systems to explain the historical evolution of social policies. In the final considerations, it presents a comparative picture of homogeny, highlighting the characteristics that bring the evolution of social policies closer to rural extension policies.
\end{abstract}

Keywords: Rural extension. Social policy. Charity. Meritocracy. Redistribution.

\footnotetext{
* Professor do Instituto Federal de Educação, Ciência e Tecnologia do Sul de Minas, Campus Muzambinho, MG. Mestre e Doutor em Política Social na Universidade Federal Fluminense, Niterói, RJ.

** Professor Associado da Universidade Federal Fluminense, Departamento de Comunicação Social, Niterói, RJ. Pós-doutor em Comunicação na Universidade Carlos III de Madrid.
} 


\section{Introdução}

No contexto das transformações estruturais observadas tardiamente em terras brasileiras na década de 1930, oriundas da transição do modelo primário exportador rumo à substituição das importações, recrudesce o capitalismo industrial e a intensificação da exploração da força de trabalho. Se por um lado a industrialização surgente mitiga a dependência de capitais externos e proporciona a formação de uma nova classe média urbana, por outro, modifica drasticamente a dinâmica socioespacial do território através do êxodo rural, culminando na formação do exército industrial de reserva nas cidades. Por consequência, ocorre a deterioração dos níveis de desigualdade social e as expressões da pobreza reverberam, demandando outrossim, a estruturação de mecanismos de amparo aos que estão à margem do sistema.

O Estado brasileiro, do mesmo modo, atrasa no estabelecimento de ações institucionalizadas de proteção social, salvo algumas iniciativas de caráter pontual voltadas ao atendimento de demandas específicas, efetivadas entre o fim do século XIX e as três primeiras décadas do Século XX. Com maior ênfase, o socorro aos desvalidos na República Velha ficou a cargo das associações de socorro mútuo ou do auxílio das pessoas mais abastadas da sociedade. Sucedendo este período laisseferiano, o período de 1930 e 1964 particularizou-se pelo viés populista/desenvolvimentista, contudo garantidor da presença do Estado na proteção social. Neste período, também surgem ações ocasionais e de origem paraestatal, assumindo especial destaque, pela miríade de interesses em disputa, a política social de extensão rural no Brasil ${ }^{1}$, institucionalizada em 1948.

Não cabe neste artigo o detalhamento amiúde do percurso histórico das políticas sociais e dos sistemas de proteção social. Contudo, à guisa introdutória, cumpre tecer algumas considerações sobre as motivações do Estado para incorporá-las. Neste ínterim, a temática é questão de fundo para destacar as similitudes da evolução histórica das políticas sociais e da institucionalização da política de extensão rural no Brasil.

Vianna (2002) evidencia a falta de consenso da literatura especializada e os limites do conceito de política social, o qual declara manifestamente vago. Para a autora, a

\footnotetext{
1 Consiste em uma das modalidades da política setorial agrícola cujo objetivo é promover o desenvolvimento agrícola e/ou rural, através de objetivos e público-alvo historicamente variáveis, mas sempre voltados para aspectos econômicos, visando ao aumento da produção e produtividade agropecuária e o bem-estar social no meio rural (RODRIGUES, 1997).
} 
bibliografia delimita o conceito nas sentenças: "ação governamental", "com objetivos específicos" e "relacionados à proteção social". Porém, chama a atenção para duas armadilhas que, ao serem desmontadas, permitem maior precisão conceitual: a primeira se refere à "ação de governo", visto que qualquer política pública pode ser criada sob distintos arranjos legais e institucionais, em diversos sistemas e regimes políticos, resultante de pressões sociais ou empreendidas por tecnocratas. A segunda armadilha concerne à expressão "objetivos específicos", onde mais uma vez urge a necessidade de qualificar os objetivos da ação governamental: se ocorre em condições autoritárias ou democráticas, ou se respondem aos interesses amplos ou restritos da sociedade.

O padrão de proteção social alçado pelo Estado, através do governo, a princípio pode estar associado a redistribuição de benefícios para enfrentar as desigualdades estruturais resultantes da relação capital e trabalho. Nessa ótica, a proteção social é contrapeso fundamental às ameaças sobre a liberdade e às indigências provenientes do progresso técnico e da dominação do homem sobre o homem e a natureza, como destaca Bobbio (2004). Contudo, as armadilhas conceituais destacadas acima induzem a importantes reflexões sobre as motivações dos governos para a adoção de políticas, programas e ações de corte social, nem sempre voltados para o enfrentamento das desigualdades. Este movimento pendular resulta frequentemente na dificuldade de percepção de certas políticas como sociais, face aos reduzidos efeitos decorrentes da ineficácia da máquina administrativa ou pela reprodução do status quo.

A contribuição de Offe (1984) é demasiadamente pertinente para este trabalho na complexa tentativa de demarcar os interesses econômicos, sociais e geopolíticos envolvidos na formulação e implementação das políticas sociais. O autor propõe um modelo teórico interpretativo para explicar a seletividade classista das políticas, fundadas sob a antinomia funcional entre a acumulação capitalista e sua legitimação social, a qual o Estado busca incessantemente conciliar. A acumulação refere-se ao aparato legal do Estado que permite e impulsiona a acumulação privada e afasta ameaças potenciais que possam interferir no processo, manifestando-se através das políticas públicas, especialmente as macroeconômicas e setoriais; os gastos do governo e o aparato legal que sustenta a propriedade privada, a ordem vigente e as relações entre capital e trabalho. Por outro lado, a legitimação representa a necessidade do ordenamento político de ser aceito pela sociedade, para garantir base de apoio e a reprodução do sistema. A 
dialética presente nesta construção teórica converge com as possibilidades suscitadas por Faleiros (1986), para quem as políticas sociais ora são vistas com mecanismo de manutenção de força de trabalho, outrora conquistas dos trabalhadores; como arranjos do bloco no poder ou bloco governante; como doação das elites dominantes ou instrumentos de garantia do aumento da riqueza ou dos direitos do cidadão. Em síntese, as políticas sociais podem refletir ações ex post em resposta às demandas sociais através da pressão de atores, movimentos sociais e instituições envolvidas na dinâmica; ou corresponderem aos programas elaborados ex ante pela tecnocracia estatal.

Em seu percurso histórico as políticas sociais assumiram feições variáveis. Não obstante a diversidade de instrumentos e elementos, a análise da trajetória possibilita a configuração de tipologias sobre os sistemas de proteção social, assentes sobre diferentes perspectivas, apesar de se tratarem dos mesmos recortes. Fleury (1994) propõe um modelo relacionado à evolução da natureza da proteção social, composto pelas fases: assistência social, seguro social e seguridade social. Esping-Andersen apud Fleury (1994) toma como critério a democratização social do capitalismo, sugerindo os modelos: conservador, liberal e social democrata. Neste trabalho, adota-se a tipologia de Titmuss (1958), que leva em consideração a relação entre o público e o privado e o grau de redistribuição dos sistemas de proteção. Esta abordagem também compreende três fases: residual ou caritativa, meritocrático-particularista e institucional-redistributiva.

A primeira tentativa institucionalizada de proteção social, a fase residual ou caritativa na tipologia de Titmuss, teve origem na Europa Ocidental, na consolidação dos modernos Estados nacionais e na transição para o capitalismo. As mudanças estruturais demandaram esforços das administrações públicas que passaram a adotar ações de proteção social em resposta à visibilidade da pobreza, ocupando espaço até então exclusivo da Igreja Católica. As "Leis dos Pobres", inicialmente criada na Inglaterra em 1601 e disseminada por outros países europeus, foram as respostas encontradas entre os Séculos XVII e XIX, em tempos de monarquias absolutistas, para a pobreza que se tornou inconveniente pelo risco social que representava. Malgrado às diferenças marcantes entre elas, apresentavam em comum o amparo à indigência através da caridade compulsória, financiadas por fundos públicos, o "imposto dos pobres", comumente recolhidos pelas municipalidades. Se por um lado os Estados, com motivação higienista, se mobilizaram para proteger a sociedade pelos riscos representados pela pobreza (doenças, furtos, 
degradação de costumes), através do recolhimento aos asilos, complementação salarial e recrutamento para o trabalho; por outro, é mister considerar que o amparo aos indigentes, desde a idade média, é associado ao ethos cristão, em busca da bemaventurança e da redenção dos pecados, coerente à purgação das iniquidades para salvação da alma por meio da obra (ALVES, 2015; VIANNA, 2002).

A segunda fase, denominada meritocrática-particularista, teve início na Alemanha no último quartil do século XIX, quando o Primeiro Ministro Bismarck criou o primeiro seguro social da história ${ }^{2}$, posteriormente implantado em outros países da Europa e de outros continentes. A característica central do modelo, como o nome sugere, reside na estreita subordinação dos benefícios sociais ao desempenho do trabalhador, superando o modelo assistencialista. Dessa maneira, as políticas sociais visam garantir ganho proporcional ao obtido no trabalho. A preocupação hegemônica com a pobreza é substituída pela ênfase na objeção ao absenteísmo - por razão de doença, acidentes ou recusa ao assalariamento - e à ação dos sindicatos operários, contestadores do sistema capitalista (FLEURY, 1994; VIANNA, 2002).

A terceira fase, institucional-redistributiva, surge em resposta à complexa conjuntura da primeira metade do século XX, marcada pelo êxito da Revolução Russa de 1917; a crise econômica internacional do final da década de 1920; duas guerras mundiais e o avanço da teoria econômica, especialmente em Keynes, conformando o cenário deste novo modelo de proteção social, empregado por praticamente todos os países desenvolvidos após a segunda guerra. O relatório Beveridge ${ }^{3}$, transformado em lei em 1946 pelo parlamento inglês, constitui o marco inicial desta fase. A partir deste momento, os Estados passam a assumir a prerrogativa de produtores de políticas destinadas a garantir amplos direitos sociais a todos os cidadãos, conformando o que se convencionou denominar Estados de bem-estar social (welfare states), com feições variáveis entre os países, mas com noção ampla dos riscos sociais e ultrapassando a fronteira da pobreza e do assalariamento das fases anteriores. Nessa fase, a política social apresenta caráter

\footnotetext{
${ }^{2}$ Diferente do que ocorreu na Dinamarca, Suécia e Inglaterra, o seguro social instituído por Bismarck não resultou do jogo parlamentar. De forma autoritária, o objetivo era muito mais político do que social, pois estava centrado no enfrentamento ao movimento operário e aos partidos trabalhista e social democrata, recém-chegados ao parlamento (VIANNA, 2002).

${ }^{3} \mathrm{O}$ relatório originou uma nova concepção de proteção social ao unificar todas as instâncias de gestão dos seguros sociais existentes, homogeneizar as prestações básicas, universalizar a cobertura para contemplar todos os indivíduos e ao prever o atendimento a todas as necessidades essenciais (VIANNA, 2002).
} 
manifestamente redistributivo, rompendo com a lógica compensatória e com o imperativo do mercado para transformar-se em ação alocativa e reguladora das imperfeições do sistema. Em consequência, a ideia de seguro dá lugar a seguridade social, que assume natureza universalista, voltado a cidadania (FLEURY, 1994; VIANNA, 2002).

Destaca-se desta breve explanação sobre a evolução das políticas sociais, as semelhanças com a historiografia da institucionalidade política da extensão rural brasileira, resguardando-se obviamente os hiatos seculares entre os acontecimentos e seu alcance. Nas seções seguintes, esse percurso será apresentado nos recortes temporais que a aproximam da evolução das políticas sociais. A periodização proposta por Rodrigues (1997) caracteriza esse processo evolutivo através de 3 binômios capazes de ressaltar o modus operandi e as concepções filosóficas dominantes em cada período: (1) humanismoassistencialista; (2) difusionismo-produtivista; e (3) humanismo-crítico. Estágios com feições assemelhadas à caridade, meritocracia e redistribuição, respectivamente. Referências mais atuais são apresentadas para ilustrar os esforços redistributivos ainda presentes, não alcançados pelo autor, ao desprazer à inflexão conservadora após 2016, aprofundada em 2019, quando as macrodefinições assumiram viés diametralmente opostos às bases principiológicas ensaiadas desde a redemocratização, quando foram alçadas à agenda pública, posteriormente materializadas em 2003, quando surge uma política nacional neste escopo. As considerações finais apresentam um quadro comparativo da analogia proposta neste ensaio.

\section{Humanismo-assistencialista: a face caritativa da extensão rural}

A institucionalidade política da extensão rural brasileira teve origem em 1948 no estado de Minas Gerais, com a criação da Associação de Crédito e Assistência Rural (ACAR), coincidindo com a entrada de serviços congêneres em toda América Latina. Delineou-se um serviço público de caráter paraestatal, através de parceria firmada entre o governo mineiro e uma associação missionária norte-americana, inaugurando assim a fase humanista-assistencialista, que perdurou até o ano de 1962 (DIAS et al., 2008; RIBEIRO, 2000; RODRIGUES, 1997;). Este período também foi o embrião de uma ideologia modernizadora de amplitude global, consubstanciada pela evolução da química e da biologia aplicada à agropecuária. A "Revolução Verde", como foi posteriormente 
denominado o período, consistiu na pesquisa e desenvolvimento de sistemas de produção agrícola para a incorporação de pacotes tecnológicos ${ }^{4}$ de suposta aplicação universal, que visavam o incremento da produtividade em distintas situações ecológicas. Seu marco histórico foi o acordo entre o Ministério da Agricultura do México e a Fundação Rockefeller, em 1943, visando o aumento da produtividade do milho, trigo e feijão.

Este marco desvela um personagem central para o objeto deste trabalho: Nelson Rockefeller, membro de uma tradicional família detentora de empresas dedicadas à exploração e comercialização do petróleo, fabricação de máquinas agrícolas, fertilizantes e produção de sementes. Rockefeller também foi um político influente ${ }^{5}$, especialmente no Governo do Presidente dos Estados Unidos, Harry S. Truman, quando atuou na concepção do programa Point Four, que recebeu esse nome por se tratar do quarto objetivo da política externa apresentado em seu discurso inaugural, em 20 de janeiro de 1949. O objetivo era conquistar "corações e mentes" no mundo em desenvolvimento, durante a guerra fria, através de programas de assistência técnica (COLBY, DENNETT, 1998; OLIVEIRA, 1999).

As ações previstas no programa Point Four, antes de serem sistematizadas pelo governo Truman, já estavam no rol da American International Association for Economic and Social Development ${ }^{6}$ (AIA) ${ }^{7}$, associação filantrópica fundada em 1946 por Rockefeller para promover assistência técnica em agricultura na Venezuela e no Brasil. Mais tarde, entre 1961 até sua extinção em 1968, a AIA passou a desenvolver atividades de pesquisa no cerrado e atuar no desenvolvimento e colonização, acompanhando o contexto da expansão territorial para o centro-oeste brasileiro. Em sua fundação, a AIA foi dividida em dois segmentos: um não lucrativo e outro lucrativo. Pouco mais tarde, em 1947,

\footnotetext{
${ }^{4}$ A expressão "pacote tecnológico", recorrente na literatura para designar característica central do modelo, não designava uma simples metáfora. Dois pesquisadores mexicanos envolvidos com o melhoramento genético tiveram a ideia de reunir em um pacote as sementes e demais insumos necessários para o plantio de uma área conhecida. Logo estes pacotes passaram a ser produzidos pelos governos e vendidos em larga escala (MATOS, 2010).

${ }^{5}$ Nelson Rockefeller também foi Governador de Nova lorque entre 1959 a 1973 e o $41^{\circ}$ vice-presidente dos Estados Unidos da América, entre 1974 e 1977. Tentou algumas vezes sem sucesso a indicação do Partido Republicano para Presidência (OLIVEIRA, 1999).

${ }^{6}$ Associação Internacional Americana para o Desenvolvimento Econômico e Social, em tradução literal.

${ }^{7}$ Por esse motivo, é um equívoco atribuir a ação de Nelson Rockefeller na Extensão Rural ao governo norteamericano.
} 
Rockefeller criou a International Basic Economy Corporation ${ }^{8}$ (IBEC), como braço lucrativo, deixando à AIA restrita as atividades filantrópicas (OLIVEIRA, 1999).

\begin{abstract}
Enquanto as equipes da AIA promoviam a criação de frangos, Nelson montava, através da IBEC, uma empresa de ração para aves. As equipes da AIA promoviam as virtudes dos fertilizantes químicos e a IBEC os vendia. A AIA encorajava o uso de sementes mais produtivas, a IBEC vendia sementes híbridas. A AIA pregou o evangelho dos pesticidas e herbicidas e a IBEC montou uma empresa de fumigação (COLBY, DENNETT, 1998, p. 251).
\end{abstract}

Sob a égide dessas concepções desenvolveram-se as primeiras ações da ACAR, importando as estratégias desenvolvidas pela AIA. Influenciado pelo modelo que seu avô John Davison Rockefeller implantou no sul e meio oeste americano, Nelson Rockefeller e seus colaboradores trouxeram ao Brasil a continuidade das ações desenvolvidas na Venezuela desde 1947, com a ação de duas organizações ao invés de uma (OLIVEIRA, 1999). A AIA, braço filantrópico, assinou convênio trienal (1949-1951) com o Governador de Minas, no dia 6 de dezembro de 1948, pelo qual o estado pagaria à época um total de Cr\$ 4,5 milhões de cruzeiros (em 3 prestações) e à AIA igual quantia. Neste processo, o governo mineiro nomeara 2 membros na Junta Administrativa e a AIA os outros 3, inclusive o Diretor Crowford, permitindo assim o controle majoritário dos empréstimos concedidos a $8 \%$ de juros por um banco estatal aos mutuários da ACAR (ACAR-MG, 1950; COLBY, DENNETT, 1998).

Na prática, a adoção deste modelo de extensão rural pelos países latinoamericanos impulsionou a estratégia de ampliação dos mercados para a comercialização de "insumos, máquinas e equipamentos produzidos pelas indústrias norte-americanas, ao mesmo tempo em que visava conter a expansão da influência do bloco de países socialistas na América Latina, no contexto da guerra fria." (ROS, 2012a, p. 26). A última preocupação é evidenciada na última frase do primeiro relatório anual da ACAR-MG, publicado em 1950: "Esta é uma das respostas da democracia aos perigos que ameaçam os povos amantes da liberdade" (ACAR-MG, 1950, p. 12).

Por outro lado, a criação da ACAR-MG em 1948 foi beneficiada por um cenário político favorável: o interregno do nacional desenvolvimentismo de Vargas, refratário ao intervencionismo. Em 1948, o Presidente era o General Eurico Gaspar Dutra, militar

\footnotetext{
${ }^{8}$ Corporação Internacional de Economia Básica, em tradução literal.
} 
liberal-conservador, que ao contrário da maioria dos seus pares, era surpreendentemente pragmático em assuntos de política externa e grande aliado do governo americano em assuntos econômicos e na guerra fria. Apesar da ausência de registros na literatura da ação direta do Presidente nas ações extensionistas, os precursores da ACAR encontraram um grande aliado no Governador de Minas Gerais Milton Campos, político liberal da União Democrática Nacional (UDN), que rompera com Vargas em 1945 para apoiar o golpe do General Dutra (COLBY, DENNETT, 1998; OLIVEIRA, 1999).

Observa-se, portanto, uma miríade de motivações e circunstâncias favoráveis ao início do serviço de extensão rural brasileiro através da ACAR-MG. Na esfera pública, os interesses norte-americanos em promover o desenvolvimento rural na América Latina, em contraponto ao que consideravam uma ameaça comunista durante a guerra fria e, da parte brasileira, o reforço aos vínculos da política externa, fortalecidas durante a segunda guerra mundial. Na esfera privada, triunfaram os interesses econômicos estrangeiros e nacionais através da reprodução social e, em grande escala, o grupo Rockefeller, em suas ações lucrativas através do IBEC. Não se pode subestimar a importância da concepção de mundo dos magnatas, que através de suas práticas filantrópicas, buscavam polir sua imagem de marca e também a necessidade de desviar ou neutralizar as aspirações de outras camadas sociais. Os filantropos priorizavam ajudar as comunidades onde fosse possível obter os melhores resultados. Esse princípio foi fundamental para a ACAR, que tinha como princípio trabalhar com os mais capazes, entre os pequenos agricultores (OLIVEIRA, 1999).

Do primeiro ano de funcionamento até meados da década de 1960, o papel da tecnologia era subjacente e o acréscimo da produção ocorria mediante expansão horizontal das fronteiras agrícolas. As ações iniciais da ACAR, apesar de incipientes, promoveram mudanças culturais e comportamentais, particularmente no que tange à adoção de tecnologias pelos pequenos produtores rurais, desempenhando importante função na gestação da agricultura tecnológica e suas vicissitudes. Em sintonia com a experiência norte-americana de extensão rural, criou-se a base estrutural de um projeto de caráter político-pedagógico, que buscava através de ações assistencialistas de legitimação, ensinar os produtores a ajudar a si mesmos. Nessa lógica, o público preferencial era o pequeno agricultor e sua família e o planejamento das ações, entre extensionista e produtores, era vertical ascendente, partindo do diagnóstico da situação, 
seguida pela especificação de alternativas baseadas nos objetivos das famílias assistidas e por fim, na tomada de decisão, geralmente elaborada pelos extensionistas e operacionalizada pela família. As ações extensionistas caracterizaram-se pela comunicação informal entre os extensionistas, produtores e sua família e pela integralidade da ação educativa - das práticas agrícolas à economia doméstica - para elevação do bem-estar social. O financiamento das práticas agrícolas e domésticas ocorria pela oferta do crédito rural supervisionado ${ }^{9}$, parte central do modelo (RODRIGUES, 1997).

\section{O difusionismo-produtivista: a meritocracia extensionista}

Com a intensificação dos processos de inovação tecnológica no campo na segunda metade do século $\mathrm{XX}$, destacando-se o acentuado desenvolvimento da motomecanização nos países desenvolvidos, configurou-se a revolução agrícola contemporânea. A partir de 1960, surge a revolução verde como uma variante desprovida de motomecanização intensiva, porém da mesma maneira assentada no melhoramento genético das grandes culturas de exportação, na adoção de fertilizantes minerais de alta solubilidade, produtos fitossanitários e, ocasionalmente, no uso da irrigação e drenagem. Desse modo, a revolução verde representou a solução apropriada para expansão capitalista nos países em desenvolvimento, entre eles o Brasil, com vastas áreas inexploradas e produtores descapitalizados. A paisagem rural se altera na medida em que surgem novos subsistemas regionais, intercalando indústrias à montante da produção agrícola, necessárias para o fornecimento dos meios de produção e à jusante, para estocar, transformar e comercializar os produtos. Em nenhum outro momento da história a produtividade agrícola, do trabalho e a rentabilidade cresceram tanto (MAZOYER; ROUDART, 2010).

Nesse contexto histórico, o final do ano de 1962 simboliza uma virada de página para a extensão rural brasileira, a despeito das ações assistencialistas da AIA terem

\footnotetext{
${ }^{9}$ O Crédito Rural Supervisionado (CRS), instituído em 1948 pela ACAR de Minas Gerais, foi uma modalidade de crédito direcionada aos pequenos produtores rurais (minifundiários, arrendatários, parceiros e ocupantes) que, em função de não auferirem rendas suficientes para realizarem as práticas agrícolas e domésticas que aprendiam, não podiam se beneficiar plenamente do serviço de extensão (SOUZA, CAUME, 2008; RIBEIRO, 2000).
} 
persistido de forma acanhada até 1968 no Sistema Brasileiro de Extensão Rural (SIBER) ${ }^{10}$. Os avanços na base técnica da agricultura e os planos governamentais, a começar pelo Plano Trienal de Desenvolvimento Econômico-social (1963-1965) ${ }^{11}$ proposto pelo Ministro do Planejamento Celso Furtado no governo do Presidente Goulart, estabeleceram diretrizes para aumentar a produção e a produtividade agropecuária. Por consequência, as instituições públicas e privadas envolvidas com a ATER, financiadas pelo poder público, passaram a ser rigorosamente requeridas no cumprimento às diretrizes estabelecidas e a partir de então, as ações passaram a fazer parte de um planejamento global de desenvolvimento do país através de instrumentos sistematizados.

Inaugura-se então um novo modelo de extensão rural voltado à difusão tecnológica, financiadas pelo crédito rural orientado ${ }^{12}$, cujos principais beneficiários foram médios e grandes produtores rurais ${ }^{13}$. De cunho tecnicista, as estratégias de desenvolvimento e intervenção negligenciavam questões culturais, sociais ou ambientais, direcionando prioritariamente suas ações aos aspectos técnicos da produção, em prejuízo das práticas de bem-estar social.

Na esfera comunicacional, a extensão rural pública passa a adotar mensagens persuasivas e indutoras de mudanças culturais e comportamentais. Ao mesmo tempo em que difundia as inovações no campo, surge nos meios de comunicação de massa a afeição pela difusão das descobertas científicas oriundas do exterior, demandando tratamento

10 Nomenclatura presente à época na legislação para designar o sistema composto pelas associações estaduais e a Associação Brasileira de Crédito e Assistência Rural (ABCAR), criada em 1956 no governo Kubitschek para coordená-lo (PEIXOTO, 2008).

${ }^{11}$ O Plano Trienal foi uma tentativa de resposta política à disparada da inflação, que se encontrava em 1963 na taxa de $78,4 \%$, à deterioração do comércio externo e ao baixo crescimento do Produto Interno Bruto.

${ }^{12} \mathrm{O}$ Crédito Rural Orientado (CRO), modalidade característica do difusionismo produtivista, direcionava-se a modernização do processo produtivo através do uso intensivo de capital. Seus principais beneficiários foram médios e grandes empresários rurais, e em alguns casos, pequenos produtores com renda suficiente para garantir a capacidade de pagamento e disposição de aceitar e receber orientação para incremento da produtividade de seu empreendimento agrícola (SOUZA; CAUME, 2008).

${ }^{13}$ A classificação atual dos imóveis rurais está presente na Lei no 8.629/1993 (Art. $4^{\circ}$, II e III), na definição de pequena propriedade (imóvel de área compreendida entre 1 e 4 módulos fiscais) e média propriedade (imóvel rural de área superior a 4 e até 15 módulos fiscais), ficando subentendido que o minifúndio é o imóvel rural com área inferior a 1 módulo fiscal, e a grande propriedade aquela de área superior a 15 módulos fiscais. O conceito de módulo fiscal, introduzido pela Lei no 6.746/1979, responsável por alterar alguns dispositivos do Estatuto da Terra (Lei no 4.504/1964), expressa a área mínima necessária para que uma unidade produtiva seja economicamente viável, levando em consideração: (a) o tipo de exploração predominante no município; (b) a renda obtida no tipo de exploração predominante; (c) outras explorações existentes no município que, embora não predominantes, sejam expressivas em função da renda ou da área utilizada; e (d) o conceito de "propriedade familiar". A dimensão de um módulo fiscal varia de 5 a 110 hectares. 
adequado das informações e um discurso voltado para o esclarecimento dos conteúdos técnico-científicos. Logo, criou-se uma narrativa voltada a incutir caráter inquestionável às ideias importadas, favorecendo a adoção das inovações sem qualquer tipo de dúvida ou questionamento. O planejamento das atividades passa a ser vertical descendente, isto é, o diagnóstico, a eleição de prioridades e as decisões sobre o que fazer competiam aos extensionistas. A tecnologia cumpriu papel finalístico para aumentar a produtividade da terra e no trabalho (RODRIGUES, 1997).

Um traço marcante da mudança de orientação para modernizar a base técnica produtiva do setor agrícola acontece quando o número de contratos de crédito rural orientado supera pela primeira vez, em 1963, as operações com o crédito rural supervisionado. Outra marca inconteste foi a substituição das equipes casadas, formadas por um extensionista agropecuário e uma extensionista doméstica, por equipes especializadas compostas por agrônomos, veterinários e técnicos em agropecuária, superando o localismo e o missionarismo em prol das questões estritamente econômicas. Também se evidencia significativa expansão do aparato institucional. A relação entre o número de extensionistas locais e o número de estabelecimentos agropecuárias, partiu de 1/6.965 em 1960, para 1/2.203 em 1970 até chegar em 1/618 em 1980. O percentual de municípios atendidos saltou de 10\% em 1960 para 40,2\% em 1960, chegando a 77,7\% em 1980 (RODRIGUES, 1997).

Após o golpe civil-militar de 1964, as novas orientações foram aprofundadas e algumas modificações no aparato estatal foram realizadas para alçar o desenvolvimento rural aos moldes da modernização conservadora e compulsória. O viés conservador da modernização refere-se ao pacto político entre a burguesia surgente à época e os proprietários de terra, numa relação de dependência da primeira em relação aos últimos, resultante da incapacidade de apresentar um projeto autônomo e hegemônico para a nação e, por conseguinte, conduzindo para uma economia dependente da dinâmica dos países desenvolvidos. Este pacto, entre outras vicissitudes relevantes, obstaculizou o acesso democrático à terra, sustentando assim uma estrutura fundiária concentrada nas mãos dos médios e grandes proprietários rurais como marca indelével da formação e evolução econômica brasileira (PIRES, RAMOS, 2009). Para Buainain (1997), o padrão de desenvolvimento vigente também foi compulsório, haja vista que, desagrado com a pretensão de neutralidade na alocação dos recursos entre os diversos cultivos, isso não 
ocorreu em virtude dos instrumentos empenhados na política agrícola resultarem em impactos assimétricos na rentabilidade dos produtos, delegando ao mercado a decisão sobre "o quê" e "quanto" produzir" e ao Estado um conjunto de ações que incidiram sobra à base técnica e a integração agroindustrial, ou seja, no "como" produzir.

Entre as políticas e ações, destacaram-se a concepção do Sistema Nacional de Crédito Rural (SNCR) em 1965 e a criação da Empresa Brasileira de Assistência Técnica e Extensão Rural (EMBRATER), em 1974, em substituição à ABCAR. Com o advento do SNCR, através da Lei 4.829, de 05 de novembro de 1965, o Estado tornou-se o principal agente promotor da modernização agrícola, estabelecendo um padrão de desenvolvimento alicerçado no latifúndio produtivo em detrimento do grande contingente de pequenos agricultores, reforçando assim o caráter meritocrático da política pública. $\mathrm{O}$ artigo $1^{\circ} \mathrm{da}$ referida lei estabelece que "o crédito rural, [...] será distribuído e aplicado de acordo com a política de desenvolvimento da produção rural do país e tendo em vista o bem-estar do povo (BRASIL, 1965). No artigo 11, delimita as modalidades de operações, compostas pelo crédito rural corrente, destinado aos produtores rurais de capacidade técnica e substância econômica reconhecidas; crédito rural orientado, como forma de crédito tecnificado, com assistência técnica prestada pelo financiador, diretamente ou através de entidade especializada em extensão rural. As outras possibilidades referem-se às cooperativas e os projetos de colonização e reforma agrária, incipientes no período (/d., 1965). A forte presença do Estado através da concessão de crédito a juros negativos impulsionou a formação dos complexos agroindustriais, bases do agronegócio contemporâneo (SOUZA; CAUME, 2008).

\section{O humanismo-crítico: a política redistributiva na extensão rural}

A década de 1980 ficou conhecida como a "década perdida" para os países da América Latina. No Brasil, a estagnação econômica, quando se verificou forte retração da produção industrial, hiperinflação e baixo crescimento do Produto Interno Bruto (PIB) resultou em perda do poder de compra da população, aumento da dívida externa e um gigantesco déficit fiscal. Este período contrastou, no plano econômico, com a década de 1970, quando ocorreu o chamado "milagre econômico brasileiro". 
No plano político, grandes foram os reflexos gerados pela superação do período autoritário em 1985, entre elas, a reorganização dos movimentos sociais, o fortalecimento do movimento ambientalista e o ressurgimento do movimento da agricultura alternativa e suas vertentes. Vários debates políticos e acadêmicos sobre agroecologia, reforma agrária e serviço público se multiplicaram e parte das demandas represadas por mais de duas décadas resultaram na Constituição Federal de 1988. O artigo 187 da Carta Magna, dedicado à política agrícola, alude à responsabilidade federal sobre a ATER em seu quarto inciso.

Entre os extensionistas brasileiros era majoritária a percepção das consequências da modernização conservadora. Nesta época, para um considerável número de extensionistas, as ideias do educador Paulo Freire, escritas em seu exílio no Chile durante a reforma agrária que se iniciou em 1968 e divulgadas em seu livro “Extensão ou comunicação?" (FREIRE, 1983), exerceram forte influência no questionamento da práxis extensionista. Na ótica freiriana, a comunicação entre o agrônomo educador e os camponeses não deveria se limitar a substituição acrítica dos conhecimentos empíricos pelas tecnologias, por maiores que sejam seus impactos sobre a produtividade. Em oposição aos "tradicionalistas" que defendiam a manutenção do "status quo" e ao "messianismo tecnicista" caracterizado pela modernização mecânica das estruturas, o autor propôs a superação da simples assistência técnica, através da conscientização dos camponeses e da autoconscientização, para que procedimentos técnicos fossem oferecidos aos educandos como problemas que eles devem responder. Neste contexto, o agrônomo educador se insere com os camponeses na transformação da realidade através da dialogicidade, como sujeito com outros sujeitos, considerando sua bagagem cultural e as implicações sociais, técnicas e ambientais da ação.

Na efervescência política do cenário da redemocratização e com o esgotamento da orientação difusionista, esboçou-se no âmbito da EMBRATER e dos debates da sociedade civil, a adoção de um modelo de extensão rural fundamentado nos ideais de Freire. Reivindicava-se a promoção humana e integral das maiorias demográficas do campo, onde a relação, outrora vertical entre extensionistas e camponeses, se transformasse em relacionamento dialógico horizontal, com o protagonismo do produtor expresso em sua capacidade de problematizar a realidade e decidir. No entanto, a resistência de setores fortalecidos no pós-redemocratização; o endividamento público e 
os objetivos do Ministério da Agricultura, focados na maior eficiência tecnológica para obtenção de safras recordes, criaram obstáculos às demandas dos movimentos sociais em ascensão. Seguindo as exigências dos organismos financeiros internacionais, a EMBRATER, em movimento ensaiado desde 1989 pelo Governo Sarney, na conhecida operação desmonte, sem êxito em função da pressão política e corporativa, foi extinta em ampla reforma administrativa conduzida em 15 de março de 1990, primeiro dia do Governo do Presidente Collor de Mello, juntamente com outras estatais, sob a alegação de que suas ações não interferiam diretamente nas dinâmicas sociais por não ofertar serviços diretos aos agricultores (ROS, 2012a).

A importante contribuição de Rodrigues (1997) que estabeleceu a periodização histórica, muito aceita nos círculos acadêmicos da extensão rural brasileira, neste ensaio relacionada à evolução das políticas sociais, encerra-se numa época em que as ações redistributivas apenas se engendravam na agenda pública através das ações das organizações dos profissionais de extensão e dos movimentos sociais campesinos reorganizados no pós-redemocratização, com especial destaque para a Associação Brasileira das Entidades Estaduais de Assistência Técnica e Extensão Rural (ASBRAER), Movimento dos Trabalhadores Rurais sem Terra (MST) e Confederação Nacional dos Trabalhadores na Agricultura (CONTAG). Contudo, alguns anos se passaram entre o ingresso na agenda, a formulação e a implementação de políticas voltadas para o humanismo-crítico.

As políticas setoriais de ATER, em crise desde 1990 pela extinção da EMBRATER, ganharam ênfase e projeção em sua formulação ainda durante o governo Cardoso (19952002), segundo Ros (2012b), através da convergência da criação e institucionalização do PRONAF, em 1995, como política de crédito rural diferenciada, reconhecendo os agricultores familiares enquanto categoria socioprofissional e permitindo o estabelecimento das bases institucionais e financeiras de apoio aos serviços de ATER; com a realização em 1997 do "Seminário Nacional de Assistência Técnica e Extensão Rural: uma nova extensão para a agricultura familiar", organizado pela CONTAG e pela ASBRAER. O evento foi precedido por seminários estaduais nas 27 unidades da federação com o objetivo de formular proposições para a construção de um novo sistema público de ATER com elegibilidade exclusiva para agricultura familiar, distinto do que prevaleceu no Brasil nas décadas anteriores, proporcionando a elaboração de novos referenciais teóricos, 
metodológicos e organizacionais basilares para a política nacional instituída anos após no governo Lula.

O projeto LUMIAR, criado em 1997 para promover o desenvolvimento autônomo dos assentamentos, também representou um importante laboratório para as elaborações correntes, na medida em que consistiu no primeiro projeto de ATER com abrangência nacional voltado exclusivamente aos assentamentos de reforma agrária e uma experiência pioneira de descentralização, ao permitir que os serviços fossem contratados pelas organizações dos próprios assentados frente às instituições públicas ou privadas credenciadas. Para Dias (2004), o projeto foi criado em conjuntura favorável a promoção da reforma agrária diante da opinião pública. As iniciativas governamentais que deram formato ao LUMIAR foram aceleradas com a repercussão internacional dos massacres de Corumbiara (1995) e Eldorado dos Carajás (1996), perpetrados pelas polícias de Rondônia e Pará em desastrosas ações de desocupação de terras, respectivamente, e fez com que o governo tomasse iniciativas concretas para incorporar a agenda da reforma agrária frente à pressão popular e para limitar a influência dos movimentos sociais, especialmente do MST, de criar fatos políticos. O autor também destaca que o projeto foi encerrado subitamente no ano 2000 por denúncias relacionadas aos desvios de recursos.

Outra iniciativa relevante do governo Cardoso foi a criação da Câmara Técnica de ATER no âmbito do Conselho Nacional de Desenvolvimento Rural Sustentável (CNDRS), cuja principal atribuição foi debater e aprovar uma proposta de política nacional de ATER para a agricultura familiar, originando a Resolução $n^{\circ} 26$, de 28 de novembro de 2001, tendo por base o documento produzido pelo Seminário de ATER de 1997 e após amplas discussões nos Conselhos Estaduais e Municipais de Desenvolvimento Rural Sustentável (ROS, 2012b).

Apesar das sólidas bases estabelecidas na resolução e nas outras relevantes ações apresentadas, a extinção da EMBRATER e, por conseguinte, do Sistema Brasileiro de Assistência Técnica e Extensão Rural (SIBRATER), resultou na considerável redução do aporte de recursos públicos federais e na quase inexistência de contratação de novos profissionais para a preservação da capacidade de prestação de serviços pelas ATERs entre a década de 1990 e início dos anos 2000, tornando as mesmas, a partir de então, dependentes dos recursos públicos estaduais e dos convênios com prefeituras, sindicatos, cooperativas etc. 
Os esforços redistributivos ultrapassaram a linha divisória entre formulação e a implementação a partir de 2003, após a posse do Presidente Lula, superando hiato de 13 anos de ausência do Estado, através de uma política voltada a educação integral, libertadora e humanista. Através do Decreto no 4.739, de 13 de junho de 2003, o Departamento de Assistência Técnica e Extensão Rural (DATER) pertencente à Secretaria da Agricultura Familiar (SAF), do Ministério do Desenvolvimento Agrário (MDA), assumiu as prerrogativas de estrutura central para coordenar os serviços dos órgãos estaduais de extensão. Em maio de 2004 foi publicada a primeira versão da Política Nacional de Assistência Técnica e Extensão Rural (PNATER), após amplos debates com a sociedade civil, realizados em 4 oficinas regionais e 1 nacional, durante o ano de 2003, aproveitando o acúmulo das formulações pretéritas.

Deste modo, a PNATER passou a orientar a adoção de novos enfoques metodológicos participativos, do paradigma tecnológico da agroecologia e da valorização do conhecimento nativo, também conceituado como tradicional ou local (DIAS et al., 2008) e "apoiar ações específicas voltadas à construção da equidade social e valorização da cidadania, visando à superação da discriminação, da opressão e da exclusão de categorias sociais, tais como as mulheres trabalhadoras rurais, os quilombolas e os indígenas." (BRASIL, 2004, p. 8). Nos 3 anos que sucederam à implementação da política, convênios e contratos foram firmados com centenas de entidades, com destaque para as 27 organizações públicas estaduais de ATER, baseadas nas diretrizes da PNATER. No período, diversos eventos de capacitação foram realizados e o orçamento federal destinado à extensão rural cresceu 12 vezes (CAPORAL, RAMOS, 2006).

Esta primeira versão da política representou o melhor cenário em que os consensos permitiram avançar, decorrentes de um processo de modificação na correlação de forças do qual as posições antes minoritárias passaram a ser adotadas como parâmetros de ação. Por um lado, consubstanciou os estudos contemporâneos da Sociologia Rural em sua crítica à modernização conservadora; no reconhecimento da agricultura familiar como categoria socioprofissional; ao considerar o "novo rural" como o ambiente onde também se fazem presentes atividades não agrícolas; ao ampliar categoricamente a noção dos beneficiários aos Povos e Comunidades Tradicionais (PCT) e a outros públicos que fazem parte da formação brasileira, tais como assentados por programas de reforma agrária, extrativistas, ribeirinhos, indígenas, quilombolas, 
pescadores artesanais, aquicultores, povos da floresta e seringueiros; e ao observar recortes de gênero, geração, raça e etnia. Também ousou ao sobrelevar o desenvolvimento rural sustentável como seu maior objetivo, sem olvidar das controvérsias associadas ao seu significado; ao sublimar o paradigma tecnológico baseado nos princípios da agroecologia; e ao estabelecer e tornar legitimamente compulsórias as metodologias participativas às organizações e entidades públicas, privadas e do terceiro setor que ensejarem captação de recursos. Por outro lado, foram construídos dois programas de ATER distintos, um deles comandado pelo INCRA, voltado especificamente para os assentamentos de reforma agrária, conhecido como Programa de Assessoria Técnica, Social e Ambiental à Reforma Agrária (ATES) e outro direcionado aos agricultores familiares, a PNATER, cuja operacionalização ficou a cargo do DATER. A consolidação de dois programas ao invés de um ocorreu em um cenário onde o INCRA era coordenado por intelectuais ligados ao MST e a estrutura do DATER/SAF comportava a influência das empresas estaduais de ATER, Organizações não Governamentais (ONGs) e dos movimentos sindicais da agricultura familiar, designadamente CONTAG, Federação dos Trabalhadores e Trabalhadoras na Agricultura Familiar (FETRAF) e Movimento dos Pequenos Agricultores (MPA); sendo que as forças ligadas ao DATER/SAF participavam da composição do CONDRAF e o MST não. Ademais, a curta experiência do LUMIAR, considerada positiva entre os assentados e suas lideranças e as discordâncias com o formato organizacional, em que as entidades estaduais de ATER ganharam força, foram particularidades que contribuíram para a criação do programa de ATES. Principalmente, porque os intelectuais próximos ao MST rejeitavam o uso das expressões "assistência técnica" e "extensão rural", para eles, herança da revolução verde e do difusionismo; e por este motivo, argumentaram que seria necessária uma ruptura total com o passado, delimitando novos conceitos e metodologias. Desse modo surgiram dois programas diferentes quanto ao público atendido e, não obstante, operacionalização semelhante quanto aos princípios e diretrizes (ROS, 2012b).

A Lei Federal 12.188, de 11 de janeiro de 2010, alterou o nome da política, que passou a ser denominada Política Nacional de Assistência Técnica e Extensão Rural para a Agricultura Familiar e Reforma Agrária (PNATER) e criou o Programa Nacional de Assistência Técnica e Extensão Rural na Agricultura Familiar e na Reforma Agrária (PRONATER). Nessa nova versão, entidades e órgãos públicos oficiais de ATER 
continuaram a ser priorizados na captação de recursos. Para participar das chamadas públicas (que surgiram em substituição aos convênios), as unidades da federação firmam termo de adesão com o MDA, através do seu conselho de desenvolvimento rural sustentável. Os objetos contratados são definidos pelo MDA e pelo Instituto Nacional de Colonização e Reforma Agrária (INCRA), quando se trata de beneficiários da reforma agrária. Para garantir celeridade na concessão dos recursos, a lei modificou o artigo 24 da Lei Federal no 8.666, de 21 de junho de 1993, que dispõe sobre a dispensa de licitação.

\section{Considerações Finais}

Desde a criação da ACAR em 1948, a política de extensão rural passou por crises e reformas que acompanharam as transformações da ordem política-institucional brasileira e a modernização da agropecuária mundial, moldando os padrões do aparato estatal dedicado aos serviços de extensão. De maneira análoga ao sistema brasileiro de proteção social, a política de extensão rural brasileira transitou entre o público e o privado; entre a caridade, a meritocracia e a redistribuição; e entre a legitimação e a acumulação. 0 Quadro 1 descreve as características dos três modelos e as homogenias sugeridas.

Quadro 1: Modelos de extensão rural e as homogenias.

\begin{tabular}{|c|c|c|c|}
\hline \multirow{2}{*}{ Características } & \multicolumn{3}{|c|}{ Modelos de extensão rural } \\
\cline { 2 - 4 } & Humanismo-assistencialista & Difusionismo-produtivista & Humanismo-crítico \\
\hline $\begin{array}{c}\text { Analogia à escala } \\
\text { de Titmuss (1958) }\end{array}$ & Residual ou caritativo & $\begin{array}{c}\text { Meritocrático- } \\
\text { particularista }\end{array}$ & $\begin{array}{c}\text { Institucional- } \\
\text { redistributivo }\end{array}$ \\
\hline $\begin{array}{c}\text { Seletividade da } \\
\text { política em Offe } \\
\text { (1984) }\end{array}$ & Legitimação & Acumulação & Legitimação \\
\hline $\begin{array}{c}\text { Prevalência } \\
\text { Público } \\
\text { preferencial }\end{array}$ & Pequenos agricultores & $\begin{array}{c}\text { Médios e grandes } \\
\text { agricultores }\end{array}$ & Pequenos agricultores \\
\hline $\begin{array}{c}\text { Unidade de } \\
\text { trabalho }\end{array}$ & Família rural & Produtor Rural & Família rural \\
\hline $\begin{array}{c}\text { Orientação } \\
\text { pedagógica }\end{array}$ & “Ensinar a fazer fazendo" & Difusionista & $\begin{array}{c}\text { Dialógica, } \\
\text { problematizadora }\end{array}$ \\
\hline $\begin{array}{c}\text { Papel do } \\
\text { extensionista }\end{array}$ & Indutor de mudanças de \\
comportamento & Elaboração de projetos de \\
crédito & $\begin{array}{c}\text { Catalizador de } \\
\text { projetos sociais }\end{array}$ \\
\hline planejamento & Vertical ascendente & Vertical descendente & Circular \\
\hline Papel da tecnologia & Subjacente & Finalístico & Essencial, mas dentro \\
\hline
\end{tabular}




\begin{tabular}{|c|c|c|c|}
\hline & & & $\begin{array}{c}\text { de padrões de } \\
\text { equilíbrio }\end{array}$ \\
\hline Crédito rural & Supervisionado & Orientado & Orientado/PRONAF \\
\hline $\begin{array}{c}\text { Organização da } \\
\text { população }\end{array}$ & $\begin{array}{c}\text { Grupos separados de } \\
\text { agricultores, donas de casa e } \\
\text { jovens }\end{array}$ & Não se preocupa & Associativismo \\
\hline
\end{tabular}

Fonte: Adaptado de Rodrigues (1997, p. 122).

Em seu primeiro momento histórico, buscou-se em atender os mais capazes entre os pequenos agricultores através de ações inicialmente financiadas e controladas por uma associação filantrópica norte-americana. A despeito das ações produtivas e de bem-estar social terem apresentado resultados econômicos e sociais imediatos, especialmente entre os mutuários, o alcance foi limitado e a pedagogia empreendida tornava o agricultor e a sua família tecnologicamente dependente dos extensionistas, visto que os saberes prévios sempre existentes não eram reconstruídos ou ressignificados criticamente, tão somente substituídos pelos conhecimentos dos extensionistas. As pronunciadas motivações geopolíticas e econômicas colaboram para o entendimento de que a ação legitimadora foi mobilizada para cumprir múltiplos propósitos, entre eles, proteger a sociedade contra o risco que representava o comunismo em tempos de guerra fria; para que os magnatas pudessem polir sua imagem de marca por intermédio da filantropia numa controversa amálgama com a busca pela bem-aventurança e redenção dos pecados; e, não menos importante, com o objetivo de promover a expansão do capitalismo na América Latina e aumentar os lucros dos desbravadores. Analogamente às leis dos pobres, a caridade foi o remédio contra os riscos representados pela pobreza.

O difusionismo-produtivista refletiu a opção do Estado brasileiro pela modernização, para incrementar a produção agrícola e industrial e superar os fatores considerados como fonte de "atraso" no meio rural. Desse modo, o difusionismo foi alçado como estratégia pedagógica para promover o encurtamento do tempo que intermedeia o lançamento de uma inovação e sua adoção coletiva pelos agricultores e, por este motivo, o modelo depositou forte ênfase na comunicação de mensagens motivadoras e persuasivas. Pelas circunstâncias históricas e objetivos manifestos, o público preferencial passou a ser formado por médios e grandes produtores rurais e, para isso, o aparato estatal dedicado à extensão rural se multiplicou. Em semelhança à fase meritocrática-particularista das políticas sociais, os benefícios alcançados subordinaram- 
se ao desempenho do trabalho, neste caso, de uma camada majoritariamente formada pela elite rural, configurando assim a opção pela acumulação.

O último momento caracteriza-se por tentativas redistributivas ainda presentes, ainda que incipientes e deveras prejudicadas pela reorientação política governamental, de garantir amplos direitos sociais aos agricultores familiares através da política de extensão rural. Impulsionado pelas ideias de Freire, pela redemocratização e pela Constituição Federal de 1988, o humanismo-crítico atravessou desde o início da sua prevalência, vácuos institucionais e pressões sistemáticas para reorientar o Estado aos moldes difusionistas, malgrado esta orientação nunca tenha sido de fato superada. $\mathrm{O}$ auge do modelo foi alcançado com a edição da PNATER em 2004, através da dialógica problematizadora e do planejamento circular entre os agentes catalizadores e produtores rurais.

Em síntese, o hiato secular entre os acontecimentos relacionados à evolução das políticas sociais e das políticas de extensão rural no Brasil sugerem a regulação social tardia, atributo comum aos países latino-americanos. Este conceito foi proposto por Sposati (2002) para caracterizar os países nos quais os direitos sociais foram reconhecidos em seus dispositivos legais no último quartil do Século $X X$, o que não significa que estejam sendo efetivamente considerados pela institucionalidade e presentes no orçamento público. Enquanto a fase redistributiva presente no modelo de Welfare State europeu, embora sob a égide do capitalismo, se desenvolveu na primeira metade do Século XX propiciando cidadania e pleno emprego; o Estado brasileiro experimenta neste período, segundo Carvalho (2005), a inversão da sequência descrita por Marshall, ao colocar a pirâmide dos direitos de cabeça para baixo. No Brasil, primeiro vieram os direitos sociais, nos anos 1930, implantados em período repressivo aos direitos políticos e civis por Getúlio Vargas, o ditador que se tornou popular, explicando em parte a inserção do clientelismo em nossa gramática política. Contudo, é importante destacar que o governo populista e desenvolvimentista de Vargas, quanto aos direitos sociais, esteve centrado na organização das relações entre o capital e os trabalhadores urbanos. Foi a Constituição Federal de 1988 que trouxe a previsão legal da universalização dos direitos sociais, ainda muito longe de serem efetivados.

Em comparação ao caso inglês, onde os direitos civis foram conquistados no Século XVIII; sucedidos um século mais tarde pelos direitos políticos e; por fim, os direitos 
sociais no Século XX; no caso brasileiro os direitos sociais foram doados segundo os interesses particulares dos governantes e das corporações, ora consoantes à acumulação, outrora à legitimação. Enquanto na Inglaterra o exercício dos direitos civis permitiu a conquista dos direitos políticos, e estes, os sociais; no Brasil, a inversão do tripé de Marshall e os direitos doados ao invés de conquistados interferem na acepção dos direitos enquanto direitos, em seu exercício e na capacidade de conquistar novos direitos (CARVALHO, 2005).

\section{Referências}

ACAR-MG. Relatório anual. Belo Horizonte: ACAR, 1950.

ALVES, I. G. Da caridade ao Welfare State: um breve ensaio sobre os aspectos históricos dos sistemas de proteção social ocidentais. Ciência e Cultura, São Paulo, v. 67, n. 1, jan./mar. 2015. Disponível em: http://cienciaecultura.bvs.br/scielo.php?pid=S000967252015 000100017\&script=sci_arttext. Acesso em: 5 mar. 2018.

BOBBIO, N. A era dos direitos. Rio de Janeiro: Elsevier, 2004. 240 p.

BRASIL. (Constituição [1988]). Constituição Federal da República Federativa do Brasil. Brasília: Presidência da República, 1988.

BRASIL. Lei Federal 12.188, de 11 de janeiro de 2010. Institui a Política Nacional de Assistência Técnica e Extensão Rural para a Agricultura Familiar e Reforma Agrária PNATER e o Programa Nacional de Assistência Técnica e Extensão Rural na Agricultura Familiar e na Reforma Agrária - PRONATER, altera a Lei n 8.666, de 21 de junho de 1993, e dá outras providências. Brasília: Presidência da República, 2010.

BRASIL. Lei $n^{\circ} 4.829$, de 5 de novembro de 1965. Institucionaliza o crédito rural. Congresso Nacional, Brasília, 1965.

BRASIL. Política Nacional de Assistência Técnica e Extensão Rural. Brasília, 2004. Disponível em: http://www.mda.gov.br/sitemda/sites/sitemda /files/user_arquivos_64 / Pnater.pdf. Acesso em: 1 mar. 2017.

BUAINAIN, A. M. Trajetória recente da política agrícola brasileira. Campinas, 1997. (Projeto UTF/FAO/036/BRA).

CAPORAL, F. R.; RAMOS, L. F. Da extensão rural convencional à extensão rural para o desenvolvimento sustentável: enfrentar desafios para romper a inércia. In: MONTEIRO, D. M. C.; MONTEIRO, M. A. (org.). Desafios na Amazônia: uma nova Assistência Técnica e Extensão Rural. Belém: UFPA/NAEA, 2006. v. 1, p. 27-50.

CARVALHO, J. M. Cidadania no Brasil: o longo caminho. 7. ed. Rio de Janeiro: Civilização Brasileira. 2005. 
COLBY, G.; DENETT, C. Seja feita a vossa vontade. Rio de Janeiro: Record, 1998. 1060 p.

DIAS, C. E. A.; FERT NETO, J.; COMUNELLO, F.; SAVIAN, M. Enfoques metodológicos participativos e agroecologia na política nacional de assistência técnica e extensão rural. Revista de Ciências Agroveterinárias, Lages, v. 7, n. 1, p. 48-53, 2008.

DIAS, M. M. Extensão rural para agricultores assentados: uma análise das boas intenções propostas pelo "Serviço de ATES". Cadernos de Ciência \& Tecnologia, Brasília, v. 21, n. 3, p. 499-543, set./dez. 2004.

FALEIROS, V. P. O que é política social. 2. ed. São Paulo: Brasiliense, 1986.

FLEURY, S. Estado sem cidadãos: seguridade social na América Latina. Rio de Janeiro: Editora Fiocruz,1994. 252 p. E-book. Disponível em: http://books.scielo.org/id/ jm5wd/pdf/fleury-9788575412428.pdf. Acesso em 15 mar. 2018.

FREIRE, P. Extensão ou comunicação? 7. ed. Rio de Janeiro: Paz e Terra, 1983. 93 p.

MATOS, A. K. V. Revolução verde, biotecnologia e tecnologias alternativas. Cadernos da FUCAMP, Campinas v. 10, n. 12, p. 1-17, 2010.

MAZOYER, M.; ROUDART, L. História das agriculturas no mundo: do neolítico à crise contemporânea. São Paulo: Editora UNESP: Brasília, DF: NEAD, 2010. 568 p.

OFFE, C. Dominação de classe e sistema político: sobre a seletividade das instituições políticas. In: Problemas estruturais do Estado capitalista. Rio de Janeiro: Tempo Brasileiro, 1984. p.140-177.

OLIVEIRA, M. M. As circunstâncias da criação da extensão rural no Brasil.Cadernos de Ciência \& Tecnologia, Brasília, v. 16, n. 2, p. 97-134, maio/ago. 1999.

PEIXOTO, M. Extensão rural no Brasil: uma abordagem histórica da legislação. Brasília: Consultoria Legislativa do Senado Federal, 2008. (Texto para Discussão n. 48). Disponível em: https://www2.senado.leg.br/bdsf/handle/id/136891. Acesso em: 30 ago. 2019.

PIRES, M. J. S.; RAMOS, P. O termo modernização conservadora: sua origem e utilização no Brasil. Revista Econômica do Nordeste, Fortaleza, v. 40, n. 3, p. 411-424, jul./set. 2009. Disponível em: https://ren.emnuvens.com.br/ren/article/view/367/315. Acesso em: 4 set. 2019.

RIBEIRO, J. P. A saga da extensão rural em Minas Gerais. São Paulo: Annablume, 2000.

RODRIGUES, C. M. Conceito de Seletividade de políticas públicas e sua aplicação no contexto da política de extensão rural no Brasil. Cadernos de Ciência \& Tecnologia, Brasília, v. 14, n. 1, 1997. p. 113-154.

ROS, C. A. Gênese, desenvolvimento, crise e reformas nos serviços públicos de extensão rural durante a década de 1990. Mundo Agrário, La Plata, v. 13, p. 1-40, 2012a. 
ROS, C. A. O processo de construção da Política Nacional de Assistência Técnica de Assistência Técnica e Extensão Rural do governo Lula (2004-2010). 2012b. Disponível em: http://www.relaser.org/index.php/. Acesso em: 10 jan. 2019.

SOUZA, C. B.; CAUME, D. J. Crédito rural e agricultura familiar no Brasil. In: CONGRESSO DA SOCIEDADE BRASILEIRA DE ECONOMIA, ADMINISTRAÇÃO E SOCIOLOGIA RURAL, 46., 2008, Rio Branco. Anais [...]. Rio Branco: SOBER, 2008.

SPOSATI, A. Regulação social tardia: característica das políticas sociais latino-americanas na passagem entre o segundo e terceiro milênio. In: CONGRESO INTERNACIONAL DEL CLAD SOBRE LA REFORMA DEL ESTADO Y DE LA ADMINISTRACIÓN PÚBLICA, 7., 2002 Lisboa, Portugal. Anais [...]. Lisboa, Portugal, 2002. Disponível em: http://www1.londrina.pr.gov.br/dados/images/stories/Storage/ sec_assistencia/pdf/Regulacao_social_tardia_Aldaisa.pdf. Acesso em: 7 mar. 2018.

TITMUSS, R. Essays on the welfare state. London: George Allen and Unwin Ltd, 1958.

VIANNA, M. L. T. W. Em torno do conceito de política social: notas introdutórias. Rio de Janeiro, dezembro de 2002. Disponível em:

www.enap.gov.br/downloads/ec43ea4fMariaLucia1.pdf. Acesso em: 5 fev. 2018.

Recebido em: 10/10/2018

Aceito em: 11/11/2019 